\title{
Ethyl pyruvate treatment ameliorates pancreatic damage: evidence from a rat model of acute necrotizing pancreatitis
}

\author{
Serdar Turkyilmaz ${ }^{1}$, Arif Burak Cekic ${ }^{1}$, Arif Usta ${ }^{1}$, Etem Alhan ${ }^{1}$, Birgül Vanizor Kural ${ }^{2}$, Cengiz Ercin ${ }^{3}$, \\ Kutay Sağlam ${ }^{4}$
}

\begin{abstract}
${ }^{1}$ Department of General Surgery, Karadeniz Technical University, Trabzon, Turkey ${ }^{2}$ Department of Biochemistry, Karadeniz Technical University, Trabzon, Turkey ${ }^{3}$ Department of Pathology, School of Medicine, Kocaeli University, Kocaeli, Turkey ${ }^{4}$ Department of Surgery, Samsun State Hospital, Samsun, Turkey
\end{abstract}

Submitted: 11 August 2016

Accepted: 10 September 2016

Arch Med Sci 2019; 15, 1: 232-239

DOI: https://doi.org/10.5114/aoms.2017.65231

Copyright (c) 2017 Termedia \& Banach

\section{Abstract}

Introduction: Ethyl pyruvate (EP), a natural flavoring and fragrance agent, has been shown to exert anti-inflammatory and antioxidant actions. We tested the potential beneficial effects of EP in a rat model of acute necrotizing pancreatitis (ANP), a serious condition with a significant inflammatory explosion and oxidative stress.

Material and methods: Fifty-two adult male Sprague-Dawley rats were divided into four groups: sham + saline, sham + EP, ANP + saline, and ANP + EP. The ANP was induced by glycodeoxycholic acid and cerulein. Animals were sacrificed at $48 \mathrm{~h}$ and biochemical, hematological, and histological markers of ANP and inflammation were assessed. The extent of mortality, systemic cardiorespiratory variables, pancreatic microcirculation, renal/hepatic functions, acinar cell injury and enzyme markers for pancreas and lung tissues were investigated.

Results: The EP-treated ANP group presented significantly lower mortality than the untreated ANP group (44\% (7/16) vs. $19 \%(3 / 16)$, respectively, $p<$ 0.05). Administration of EP resulted in significantly lower levels of IL-6 (ANP + saline: $5470 \pm 280$ vs. ANP + EP: $2250 \pm 180$ pg/ml, $p<0.05$ ). Compared with the ANP group, the ANP + EP group had a lower pancreatic necrosis score $(1.45 \pm 0.2$ vs. $0.96 \pm 0.2, p<0.05)$. Moreover, intraperitoneal EP administration had a positive effect on most indices of pancreatitis (amylase and alanine transaminase levels) and lung damage (except lung malondialdehyde levels) as they decreased towards baseline values.

Conclusions: The results from this experimental study indicate that EP, a nontoxic chemical approved by the Food and Drug Administration as a food additive, provides positive effects on the course of pancreatitis, suggesting potential usefulness in management of ANP.

Key words: pancreatitis, rat, ethyl pyruvate, acute necrotizing pancreatitis.

\section{Introduction}

Acute pancreatitis, a sudden onset inflammatory condition of the pancreas, is a mild and self-limiting disease that usually resolves spontaneously or by simple supportive therapy in most patients. However, in about $10-20 \%$ of patients, the course of acute pancreatitis can take

\author{
Corresponding author: \\ Dr. Serdar Turkyilmaz \\ Department of General \\ Surgery \\ Faculty of Medicine \\ Karadeniz Technical \\ University \\ Farabi Hospital \\ 61080 Trabzon, Turkey \\ Phone: +90 4623775454 \\ +90533 3570984 \\ E-mail: serdarturkyilmaz@ \\ yahoo.com
}


the severe or necrotizing form, which generally requires prolonged periods of intensive care hospitalization with high costs, and significant morbidity and mortality rates. Despite recent improvements in medical management and care, the mortality of acute necrotizing pancreatitis (ANP) is still about $6.2 \%$ to $20.8 \%$, and when the pancreas is infected this rate may be exceeded, largely due to sepsis and multiorgan failure [1, 2].

Pancreatic damage occurs by autodigestion of the pancreas when pancreatic enzymes are activated before being released into the intestine. As a result of attack of own tissue by these enzymes, pancreatic damage and impairment in pancreatic microcirculation are the typical two main events in the process of acute pancreatitis [1, 2]. The symptoms of acute pancreatitis may range from mild abdominal discomfort to severe pain, and at times this debilitating disease may become severe and life-threatening.

Experimental and clinical data indicate that the release of inflammatory mediators and subsequent activation of cytokines and collection of secondary mediators such as histamine, thromboxanes, prostaglandins, nitric oxide, leukotrienes, and platelet-activating factor from the pancreas and from various other sources play an important role in the course of acute pancreatitis leading to tissue destruction [1, 3, 4]. In the early phase, the disease is accompanied by hypovolemia, manifesting as hypotension and tachycardia, resulting from fluid sequestration into the abdominal cavity. If the resolution fails to occur, infection of pancreatic necrosis usually develops by translocation of enteric bacteria, and this may lead to multiorgan failure $[1,5]$.

Accumulating evidence indicates that reactive oxygen species (ROS) contribute to the pathogenesis of acute pancreatitis [6] locally in the pancreas and remote organs, both in the early and late stages. The exact site and source of enhanced ROS generation in the initial stages of this disease are not clear. In later stages, the attraction and activation of leukocytes in the pancreas cause enhanced ROS production [7]. It is well documented that ROS directly attack cell membrane lipids and proteins and disrupt their functions. The ROS also exert indirect actions, through action on the arachidonic metabolism, on these membrane structures [8]. The latest effect involves stimulation of increased secretion of thromboxane, which decreases tissue circulation due to its platelet aggregating and vasoconstricting actions. The ROS also cause increased production of leukotriene $B_{4}$, which enhances the activation of leukocytes and the release of lysosomal enzymes [8]. As a vicious cycle, these processes lead to further cell damage of the pancreas. There is also experimental and clinical evidence on the role of ROS in acute pancreatitis $[6,9,10]$. Different experimental models and clinical studies indicate that antioxidants and free radical scavengers including melatonin provide significant beneficial effects on pancreatitis [11].

Pyruvate, the anionic form of 2-oxo-propionic acid, is the final product of glycolysis before entering the tricarboxylic acid cycle. Pyruvate is also a scavenger of ROS such as hydroxyl radical [12]. Ethyl pyruvate (EP) is an endogenous derivative of pyruvate. EP is known to exert more effective anti-oxidative and anti-inflammatory actions $[13,14]$. There is experimental evidence that EP significantly protects against ischemia/reperfusion-induced intestinal mucosal injury, and also prevents liver injury secondary to $\operatorname{ANP}[15,16]$. Although previous experimental studies $[15,16]$ have successfully documented that EP ameliorates distant organ injury and reduces mortality in experimental ANP, they did not evaluate pancreatic microcirculation in detail. It is well documented that impairment of pancreatic microcirculation plays a key role in the pathogenesis of ANP. Considering the fact that microcirculation plays a crucial role in both physiological and pathophysiological states including ANP, analysis of microcirculation of the pancreas by orthogonal polarization imaging a video microscope provides a unique perspective to document impairment and assess possible effects of therapy on pancreatic microcirculation $[17,18]$. This method has been successfully validated in a wide spectrum of experimental and limited clinical applications for assessment of functional capillary microcirculation $[17,18]$.

The aim of this study was to investigate possible effects of EP on ANP in a rat model of acute pancreatitis. Effects of EP on the parameters of extent of acinar cell damage, functional microcirculatory parameters (functional capillary density - FCD), systemic cardiorespiratory variables, evaluation of hepatic and renal functions, changes in some enzyme markers for pancreas and lung tissue, and mortality rates were investigated.

\section{Material and methods}

\section{Animals}

Fifty-two male Sprague Dawley rats (300-350 g) were used. The animals were housed in standard conditions $\left(21 \pm 1^{\circ} \mathrm{C}\right.$ and a $12: 12$-h light/dark cycle) with free access to water. During the study period the animals were housed in metabolic cages, one in each cage, which enabled quantitative assessment of urine output. The protocol of this study was approved by the Ethics Committee of Karadeniz Technical University (Trabzon, Turkey, protocol number: 2009/11, date: 12.05.2009). 


\section{Experimental procedures}

After overnight fasting, animals were anesthetized using vaporized ether for induction and intraperitoneal ketamine injection at $50 \mathrm{mg} / \mathrm{kg}$ (Ketalar, Eczacıbası, Istanbul, Turkey) for the maintenance of surgical anesthesia. For infusion, blood sampling and hemodynamic measurements the right internal jugular vein and carotid artery were cannulated (Luer Lock, ID $0.5 \mathrm{~mm}$, Braun AG, Melsungen, Germany). The catheters were tunneled subcutaneously to the suprascapular area.

Acute pancreatitis was induced as previously described by Schmidt et al. [19]. Briefly, cerulein (Sigma-Aldrich Chemie GmbH, Steinheim, Germany) was given by intravenous infusion at a dose of $5 \mathrm{mg} / \mathrm{kg} / \mathrm{h}$ over $6 \mathrm{~h}$ superimposed on a standard infusion of $1.2 \mathrm{ml} / \mathrm{kg}$ glycodeoxycholic acid (10 mmol/l, Sigma, St. Louis, USA) into the biliary-pancreatic duct for $10 \mathrm{~min}$ at $30 \mathrm{~mm} \mathrm{Hg}$ through an infusion pump for pressure and volume control (Hampshire, United Kingdom, Alaris Medical Systems, RG22, 4BS, IVAC P 7000). For the baseline hydration, saline containing cerulein was infused at $8 \mathrm{ml} \mathrm{ml} / \mathrm{kg} / \mathrm{h}$. The animals in the sham group were given intraductal saline followed by a 6-h intravenous saline infusion.

Rats were randomly divided into four groups (Figure 1). Group I (sham + saline, $n=10$ ) received intraductal saline followed by a 6 -h intravenous infusion of saline at $8 \mathrm{ml} / \mathrm{kg} / \mathrm{h}$. During the following 6-h period $1 \mathrm{ml}$ of saline was given intravenously, and saline was infused $(6 \mathrm{ml} / \mathrm{kg}$, i.v. $)$ for the last $18 \mathrm{~h}$. At $24 \mathrm{~h}$ after the beginning of the experiment, the cardiorespiratory function was assessed by monitoring the arterial blood gases, mean arterial pressure (MAP), renal function by the collection of urine output, and survival was recorded. To ensure reliable pancreatic microcirculation measurement, rats with MAP of $<80 \mathrm{~mm} \mathrm{Hg}$, partial pressure of oxygen $\left(\mathrm{pO}_{2}\right)$ of $<80 \mathrm{~mm} \mathrm{Hg}, \mathrm{pCO}_{2}$ of $>50 \mathrm{~mm} \mathrm{Hg}$, and $\mathrm{pH}$ of $<7.3$ and dead rats were excluded from the study. At $24 \mathrm{~h}$, laparotomy was performed under ketamine/xylazine anesthesia. The pancreas and spleen were exposed on an adjustable stage. The orthogonal polarization imaging video microscope (Cytoscan A/R, Cytometrics, Philadelphia,
PA, USA) was attached to the moveable shaft and the microcirculation was recorded in six different capillary regions of the exocrine pancreas for at least $20 \mathrm{~s}$ [17]. Orthogonal polarization imaging was used to measure pancreatic microcirculation $[17,18]$. Recorded data were evaluated using an automated microvascular analysis system (MAS, Microvascular Analysis Software, Microvision Medical BV). The FCD was defined as the length of red blood cell-perfused capillaries (in centimeters) per observation area (in square centimeters). Hence we selected FCD as the parameter for measurement of the pancreatic microcirculation. The images were stored in $\mathrm{AVI}$ format on a computer (Sony VGN-FW 230J/H).

Blood samples were taken from the carotid artery for the measurements of serum concentrations of electrolytes, calcium, urea, creatinine, and glucose and activities of amylase, alanine aminotransferase (ALT), and interleukin (IL)-6. A midline sternotomy was performed and the left main bronchus was clamped. Bronchoalveolar lavage (BAL) of the right lung was performed with $2 \mathrm{ml}$ of phosphate-buffered saline containing $0.07 \mathrm{M}$ ethylenediamine tetraacetic acid, and this procedure was repeated twice. The combined lavage of approximately $6 \mathrm{ml}$ was centrifuged at $1,500 \mathrm{rpm}$ for $20 \mathrm{~min}$ at $4^{\circ} \mathrm{C}$, frozen at $-20^{\circ} \mathrm{C}$, and assessed subsequently for lactate dehydrogenase (LDH) measurement [20]. The left lung was harvested for the measurements of the activity of the myeloperoxidase (MPO) and malondialdehyde (MDA) levels. The excised lung tissues were rinsed in saline, blotted dry, immediately frozen in liquid nitrogen, and stored at $-80^{\circ} \mathrm{C}$ until MPO and MDA activity assay. At the end of the experiment, the entire pancreas was removed and divided into two samples, one for the histological examination and the other for the measurements of MPO and MDA activity.

In group II (sham $+E P, n=10)$ animals received $\mathrm{EP}$ at $40 \mathrm{mg} / \mathrm{kg}$ body weight, given intraperitoneally at the $6^{\text {th }}$ hour. The other procedures were the same as described for the first group. Group III (ANP + saline, $n=16$ ) animals were treated according to the protocol of group 1 after the induction of ANP. In group IV (ANP + EP, $n=16)$, after induction of

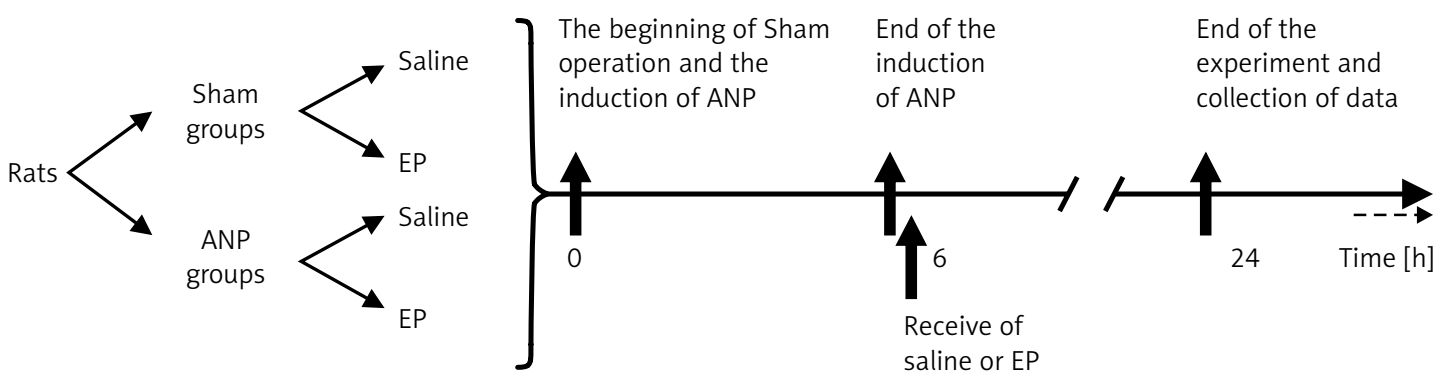

Figure 1. Experimental design and time schedule of the study 
ANP, EP was given as described for group 2. Saline and EP were given $6 \mathrm{~h}$ after the induction of ANP. In small animals, as ANP occurs four to six times faster than humans and most patients with acute pancreatitis are admitted 24-36 h after the onset of pancreatitis, this period is shorter in order to mimic the clinical situation [21].

\section{Blood pressure monitoring and biochemical analysis}

Blood pressure was monitored (Petas KLM 200, Istanbul, Turkey) through a calibrated pressure transducer which was connected to the arterial line. The blood gas analysis were performed using a Ciba Corning 865 analyzer (Chiro Diagnostica Co, East Walpole, MA, USA).

Serum activities of amylase and ALT and the concentrations of glucose, creatinine, urea, calcium, LDH in BAL, and the electrolytes were measured by an autoanalyzer (Vitros 750 autoanalyzer, Johnson \& Johnson, Rochester, NY, USA).

Serum IL- 6 analysis was performed using enzyme-linked immunosorbent assay (ELISA) (Sanofi Diagnostic Pasteur, Marnes la Coquette, France) with a commercial kit (Biosource Interleukin 6 CB) [22]. The MPO activity was expressed as units per milligram of protein. The MDA measurements were carried out using a colorimetric reaction with thiobarbituric acid by modification of the method described by Buege and Aust [23]. MDA concentrations were expressed as nanomoles per milligram of protein. The protein concentrations of supernatants were measured as described by Lowry [24].

\section{Morphologic examination}

Half of the pancreas tissue was stained with hematoxylin-eosin after being fixed in 10\% buffered formalin. Histopathological evaluation of each specimen was performed by an experienced pa- thologist who was blinded to the groups. Necrosis, edema and leukocyte infiltration were classified using a scoring system from 0 to 3 at histopathological investigation. Tissue preparations in which no pathologic changes were observed were scored as 0 , while total pancreas necrosis or maximum inflammatory changes were scored as 3 [19].

\section{Statistical analysis}

Data are presented as the mean \pm SEM. Statistical analyses were performed using SPSS (Statistical Package for the Social Sciences, version 11.5 for Windows, SPSS Inc, Chicago, IL). The difference between the experimental groups with respect to the survival rates was assessed using Fisher's exact test. Histopathological data and enzyme activities were analyzed using Kruskal-Wallis and Mann-Whitney $U$ tests. A $p$-value of $<0.05$ considered as statistically significant.

\section{Results}

Mortality rates for groups were as follows: 0\% in the sham + saline group, $43.75 \%$ in the ANP + saline group, $0 \%$ in the sham + EP group, and $18.75 \%$ in the ANP + EP group. Induction of pancreatitis caused significant mortality rates in the pancreatitis groups, while no mortality was observed in the sham groups $(p<0.05$; Table I). Mortality was lower in the EP-treated ANP group than the untreated ANP group (44\% (7/16) vs. 19\% (3/16), respectively, $p=0.05$ ) (Table I).

Administration of EP effectively restored the ANP-induced significant decrease in MAP, and reduction of urine output, $\mathrm{pO}_{2}$ and pancreatic microcirculation (Table I).

Serum activity of amylase, ALT, IL-6, and serum urea was significantly higher and serum calcium concentration was significantly lower $(p<0.05$; Table II, Figure 2) following the induction of ANP.

Table I. Systemic hemodynamic variables, blood gas analysis, mortality and functional capillary density at $24 \mathrm{~h}$ (data are given as mean \pm SEM)

\begin{tabular}{|lcccc|}
\hline Parameter & $\begin{array}{c}\text { Sham }+ \text { saline } \\
\boldsymbol{N}=10\end{array}$ & $\begin{array}{c}\text { Sham }+ \text { EP } \\
\boldsymbol{N}=10\end{array}$ & $\begin{array}{c}\text { ANP }+ \text { saline } \\
\boldsymbol{N}=9\end{array}$ & $\begin{array}{c}\text { ANP + EP } \\
\boldsymbol{N}=13\end{array}$ \\
\hline $\mathrm{MAP}[\mathrm{mm} \mathrm{Hg}]$ & $129 \pm 8$ & $128 \pm 7$ & $84 \pm 4^{*}$ & $118 \pm 8$ \\
\hline $\mathrm{HR}[\mathrm{beat} / \mathrm{min}]$ & $322 \pm 19$ & $329 \pm 17$ & $397 \pm 18$ & $402 \pm 22$ \\
\hline $\mathrm{pH}$ & $7.36 \pm 0.04$ & $7.36 \pm 0.03$ & $7.3 \pm 0.04$ & $7.31 \pm 0.03$ \\
\hline $\mathrm{pO}_{2}[\mathrm{~mm} \mathrm{Hg}]$ & $108 \pm 4$ & $105 \pm 4$ & $82 \pm 3^{*}$ & $98 \pm 4$ \\
\hline $\mathrm{pCO}_{2}[\mathrm{~mm} \mathrm{Hg}]$ & $34 \pm 4$ & $33 \pm 3$ & $37 \pm 3$ & $38 \pm 4$ \\
\hline Urine $[\mathrm{ml} / \mathrm{h}]$ & $0.7 \pm 0.1$ & $0.7 \pm 0.1$ & $0.3 \pm 0.1^{*}$ & $0.6 \pm 0.1$ \\
\hline Death & $0 / 10$ & $0 / 10$ & $7 / 16^{* *}$ & $3 / 16^{\star *, * \alpha}$ \\
\hline FCD $\left[\mathrm{cm} / \mathrm{cm}^{2}\right]$ & $32 \pm 3$ & $33 \pm 2$ & $21 \pm 2^{*}$ & $28 \pm 2$ \\
\hline
\end{tabular}

ANP - acute necrotizing pancreatitis, EP - ethyl pyruvate, $F C D$ - functional capillary density, $H R$ - heart rate, MAP - mean arterial pressure. ${ }^{*} p<0.05$, versus other groups, ${ }^{* \alpha} p<0.05$ compared with ANP + saline group, ${ }^{* *} p<0.005$ compared with sham groups. 
Table II. Serum IL-6, tissue concentrations of MPO and MDA, LDH levels in BAL, serum levels of amylase, and the other biochemical parameters at $24 \mathrm{~h}$ in animals with or without ANP treated with saline or ethyl pyruvate (data are given as mean \pm SEM)

\begin{tabular}{|c|c|c|c|c|}
\hline Parameter & $\begin{array}{c}\text { Sham + saline } \\
N=10\end{array}$ & $\begin{array}{c}\text { Sham + EP } \\
N=10\end{array}$ & $\begin{array}{c}\text { ANP + saline } \\
\quad N=9\end{array}$ & $\begin{array}{c}\mathrm{ANP}+\mathrm{EP} \\
N=13\end{array}$ \\
\hline Amylase [U/I] & $1632 \pm 22$ & $1570 \pm 33$ & $12300 \pm 380^{* *}$ & $9128 \pm 580^{* *, * \alpha}$ \\
\hline Glucose [mg/dl] & $77 \pm 15$ & $81 \pm 12$ & $101 \pm 8$ & $119 \pm 15$ \\
\hline Urea [mg\%] & $18 \pm 4$ & $17 \pm 3$ & $55 \pm 7^{*}$ & $22 \pm 3^{\star_{\alpha}}$ \\
\hline $\begin{array}{l}\text { Creatinine } \\
{[\mathrm{mg} \%]}\end{array}$ & $0.45 \pm 0.1$ & $0.44 \pm 0.1$ & $0.46 \pm 0.1$ & $0.45 \pm 0.1$ \\
\hline $\mathrm{ALT}[\mathrm{U} / \mathrm{I}]$ & $67 \pm 7$ & $69 \pm 8$ & $220 \pm 17^{*}$ & $142 \pm 12^{\star \star * \star \alpha}$ \\
\hline Calcium [mg\%] & $8.9 \pm 0.2$ & $9.1 \pm 0.2$ & $8 \pm 0.2^{*}$ & $8.5 \pm 0.2^{\star \alpha}$ \\
\hline $\mathrm{BAL} \mathrm{LDH}[\mathrm{U} / \mathrm{I}]$ & $364 \pm 22$ & $369 \pm 24$ & $790 \pm 82^{*}$ & $313 \pm 26$ \\
\hline IL-6 [pg/ml] & $870 \pm 65$ & $925 \pm 56$ & $5470 \pm 280^{* *}$ & $2250 \pm 180^{* *, * \alpha}$ \\
\hline Pancreas MDA & $0.35 \pm 0.03$ & $0.33 \pm 0.03$ & $1.05 \pm 0.04^{\star}$ & $0.5 \pm 0.06$ \\
\hline $\begin{array}{l}\text { Pancreas MPO } \\
{[\mathrm{U} / \mathrm{mg} \text { total }} \\
\text { protein] }\end{array}$ & $0.26 \pm 0.01$ & $0.23 \pm 0.02$ & $0.97 \pm 0.03^{*}$ & $0.35 \pm 0.04$ \\
\hline $\begin{array}{l}\text { Pancreas MPO } \\
{[\mathrm{kU} / \mathrm{mg} \text { MPO }} \\
\text { protein] }\end{array}$ & $2.2 \pm 0.1$ & $2.3 \pm 0.1$ & $8.2 \pm 0.3^{*}$ & $3.23 \pm 0.4$ \\
\hline Lung MDA & $0.26 \pm 0.02$ & $0.28 \pm 0.02$ & $0.90 \pm 0.04^{* *}$ & $0.87 \pm 0.04^{* *}$ \\
\hline $\begin{array}{l}\text { Lung MPO } \\
\text { [U/mg total } \\
\text { protein] }\end{array}$ & $3.3 \pm 0.03$ & $3.3 \pm 0.03$ & $5.3 \pm 0.04^{*}$ & $3.1 \pm 0.04$ \\
\hline $\begin{array}{l}\text { Lung MPO } \\
{[\mathrm{kU} / \mathrm{mg} \text { MPO }} \\
\text { protein] }\end{array}$ & $28 \pm 5$ & $26 \pm 4$ & $48 \pm 5^{*}$ & $33.9 \pm 6$ \\
\hline
\end{tabular}

$A L T$ - alanine aminotransferase, ANP - acute necrotizing pancreatitis, BAL - bronchoalveolar lavage, EP - ethyl pyruvate, $L D H$ - lactate dehydrogenase, MDA - malondialdehyde, MPO-myeloperoxidase. ${ }^{*} p<0.05$ compared with other groups, ${ }^{* *} p<0.01 \mathrm{compared}$ with sham groups, ${ }^{* a} p<0.05$ compared with ANP + saline group.

The EP treatment provided a significant recovery in these values. No significant change was detected in levels of serum glucose and creatinine in any group (Table II).

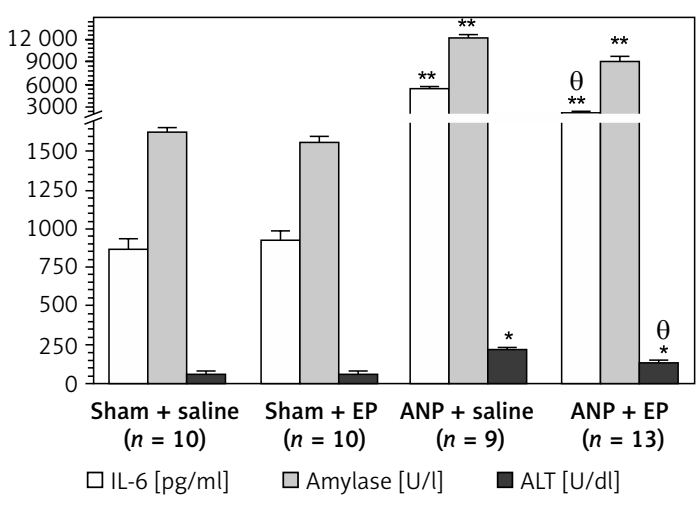

Figure 2. Serum IL-6, amylase, and BAL LDH levels among experimental groups (mean $\pm \mathrm{SEM}$ )

$E P$ - ethyl pyruvate; ANP - acute necrotizing pancreatitis. Asterisks indicate statistically significant difference $\left({ }^{*} p<0.05\right.$, ${ }^{* *} p<0.01$ compared with sham groups, ${ }^{\theta}$ compared with ANP + saline group).
Compared with the sham + saline group the ANP + saline group had significantly higher BAL $\mathrm{LDH}(364 \pm 22 \mathrm{U} / \mathrm{dl}(n=10)$ vs. $790 \pm 82 \mathrm{U} / \mathrm{dl}$ $(n=9), p<0.05)$, lung MPO (3.3 $\pm 0.3 \mathrm{U} / \mathrm{mg}$ protein $(n=10)$ vs. $5.3 \pm 0.04 \mathrm{U} / \mathrm{mg}$ protein $(n=9)$, $p<0.05)$ and lung MDA $(0.26 \pm 0.02 \mathrm{nmol} / \mathrm{mg}$ protein $(n=10)$ vs. $0.90 \pm 0.04 \mathrm{nmol} / \mathrm{mg}$ total protein $(n=11), p<0.01)$ (Table II, Figure 3$)$. There were no statistically significant differences in these values between sham + saline and sham + EP groups. When EP was administered (ANP + EP group) there was observed a less pronounced ANP-induced increase in BA LDH and lung MPO activities compared to the ANP + saline group (Table II, Figure 3), but the difference in lung MDA was not significant.

Histological examination of pancreatic tissue revealed greater edema, necrosis, and leukocyte infiltration in the ANP groups compared to the sham groups (Table III). In the ANP+EP group, the levels of pancreatic edema and necrosis were significantly lower compared to the ANP + saline group $(p<0.05$, Table III). 


\section{Discussion}

The results from this experimental study indicate that the induction of ANP caused a significant mortality rate. This was associated with a significant increase in activity of serum amylase, ALT, and IL-6, serum concentration of urea, LDH in BAL fluid, and tissue activity of MPO and MDA in the pancreas and lung. The serum concentrations of calcium, MAP, urine output, $\mathrm{pO}_{2}$ and FCD were significantly decreased. As the main aim of this study was to investigate the effectiveness of EP in experimental ANP, the administration of EP significantly restored these changes.

We utilized the experimental model of ANP as described by Schmidt et al. [19]. Because mild or moderate forms of acute pancreatitis can be self-limiting and be treated with minimal morbidity and mortality, we tested the effects of EP in the severe form of acute pancreatitis [1]. This model provides a superior opportunity to test the effectiveness of novel agents and treatment approaches for ANP by standard processes. It is documented that ANP develops about four to six times faster in small animals than in humans and most acute pancreatitis patients are admitted 24-36 h after its onset [21]. Therefore, we administered EP $6 \mathrm{~h}$ after the induction of pancreatitis. It was given as $40 \mathrm{mg} / \mathrm{kg}$ body weight, intraperitoneally at $6 \mathrm{~h}$ for a single dose. The first step in the treatment of acute pancreatitis is appropriate fluid replacement, so we used appropriate fluid replacement to restore the organ function $6 \mathrm{ml} / \mathrm{kg} / \mathrm{h}$ after the induction of ANP. Evaluations were limited to the 24-h post-pancreatitis period because the severe form of ANP does not allow long-term survival.

Ethyl pyruvate is a stable simple aliphatic ester with anti-inflammatory actions [14, 25]. Ethyl pyruvate is a comparatively safe and fast acting agent at clinically relevant doses. The only clinical study available demonstrated that $450 \mathrm{mg} /$ $\mathrm{kg} / \mathrm{day}$, given in five divided doses, was without side effects [26]. Considering this, the dose used in the current study does not exceed the safe and well-tolerated dose of EP.

It has been shown that EP decreases the release of proinflammatory cytokines such as IL$1 \beta$, tumor necrosis factor $\alpha$ (TNF- $\alpha), I L-6$, and

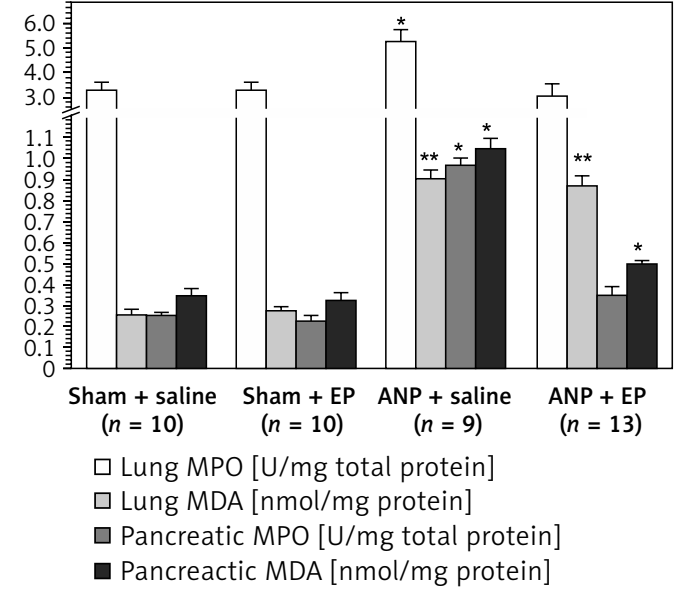

Figure 3. MPO and MDA values in the lung and pancreas tissues among study groups

MPO - myeloperoxidase, MDA - malondialdehyde, EP - ethyl pyruvate, ANP - acute necrotizing pancreatitis. Asterisks indicate statistically significant difference $\left({ }^{*} p<\right.$ $0.05,{ }^{* *} p<0.01$ compared with sham groups).

high-mobility group box 1 , and also effectively reduces ANP mortality and ameliorates extrapancreatic organ injury in pancreatitis [16, 27, 28]. In severe forms of acute pancreatitis, EP exhibits protective effects by inhibiting activation of nuclear factor- $\kappa \beta$ (NF- $\kappa \beta)[29,30]$.

Pancreatic necrosis is the hallmark of severe pancreatitis and is one of the major determinants of mortality [31]. During the course of acute pancreatitis, autodigestion, apoptosis, ischemia, and ischemia-related ROS-associated lipid peroxidation occur and mediate the pancreatic damage [1-3]. Impairment of microcirculation is another important pathogenetic factor of acute pancreatitis, and evaluation of the microcirculation provides important clues for the status of pancreatitis [3]. The microcirculation of the pancreas can be measured by diffuse reflectance spectroscopy, multiple indicator dilution technique, intravital microscopy, and orthogonal polarization imaging [21]. In the current study, pancreatic microcirculation was measured by orthogonal polarization imaging technique. Oxidative stress and ROS are important mediators in the pathogenesis of acute pancreatitis [7, 32]. In our study, induction of pancreatitis resulted in a decrease in FCD and

Table III. Histological assessment of edema, necrosis, and inflammation (values are given as mean \pm SEM)

\begin{tabular}{|lcccc|}
\hline Parameter & Sham + saline & Sham + EP & ANP + saline & ANP + EP \\
& $N=10$ & $N=10$ & $N=9$ & 13 \\
\hline Edema & $0.2 \pm 0.1$ & $0.2 \pm 0.2$ & $0.88 \pm 0.1^{* *}$ & $0.5 \pm 0.2^{* *, * \alpha}$ \\
\hline Necrosis & $0.2 \pm 0.1$ & $0.2 \pm 0.2$ & $1.45 \pm 0.2^{* *}$ & $0.96 \pm 0.2^{* *, * \alpha}$ \\
\hline Inflammation & $0.2 \pm 0.2$ & $0.2 \pm 0.2$ & $1.19 \pm 0.3^{* *}$ & $1 \pm 0.3^{* *}$ \\
\hline
\end{tabular}

ANP - acute necrotizing pancreatitis, EP - ethyl pyruvate, ${ }^{*} p<0.05$ compared with other groups, ${ }^{* *} p<0.01$ compared with sham groups, ${ }^{\star} p<0.05$ compared with ANP + saline group. 
increase in ischemic mediators such as pancreatic tissue MPO and MDA activities, which reflect oxidative stress. Administration of EP restored the decreased FCD value and increased pancreatic tissue ischemia mediators. The obtained improvement by EP treatment in our model may be due to antioxidative effects of EP. Recent evidence indicates that EP also has anticoagulant properties, and the obtained improvement in pancreatic microcirculation may also involve the anticoagulant effects of EP [33-35].

In the early stage of severe pancreatitis acute lung injury and acute respiratory distress syndrome (ARDS) often develop and have been considered among the major causes of early death [36, 37]. The production of ROS by the activated leukocytes resulting in increased capillary permeability plays a major role in the pathogenesis of ARDS. Therefore, BAL fluid LDH levels were used for capillary permeability assessment $[20,37]$. The induction of ANP resulted in increased $L D H$ in BAL fluid, decreased $\mathrm{PO}_{2}$, and increased activities of MPO and MDA in lung tissue. Administration of EP significantly reduced the lung injury associated with the pancreatitis. Matone et al. tested EP and reported similar results to our study in rat lung [38].

In acute pancreatitis, direct damage to pancreatic tissue as a result of the systemic inflammatory response and activation of various enzymes and cytokines often leads to multiorgan failure. Administration of EP provided significant improvements in the pancreatitis-induced changes in the concentration of serum urea and ALT activity and serum calcium and urine output. NF- $\kappa \beta$ activation has an important role in the progression from the localized disease to multiorgan failure in acute pancreatitis. The inhibitory effect of EP on activation of NF- $\kappa \beta$ may explain its protective effects on other organs [27, 28].

It has been shown that measurement of activation of proteolytic peptides (e.g. trypsinogen-activated peptide) and activity level of acute-phase reactant and markers of inflammation including C-reactive protein, TNF- $\alpha, \mathrm{IL}-6$, and IL-10 reliably reflect the severity and outcome of acute pancreatitis [39]. In the current study serum IL-6 was measured as a marker of inflammation and a significant improvement in serum IL-6 levels was obtained with the use of EP. The EP has an inhibitory effect on some of the pro-inflammatory cytokines through the inhibition of NF- $\kappa \beta$, and these may have mediated the observed beneficial effects of EP on ANP, as reflected by pancreatic tissue damage and the overall mortality rate $[27,28,38]$.

This study has some limitations that need to be considered when interpreting data. This is an animal study employing experimental ANP, and the translational potential needs to be confirmed by clinical studies. We demonstrated a beneficial effect of EP without clarifying the exact mechanism of action. Although there are definitely anti-oxidant effects of $E P$, the protective effects of this agent may extend beyond the anti-oxidant influences and include anti-inflammatory actions. We used a single dose and single administration of EP; considering the obtained beneficial effect of chronic application, higher doses are warranted.

In conclusion, we examined the effect of EP, a novel endogenous metabolite with prominent anti-inflammatory and antioxidant activity, in a severe form of experimental ANP and found that EP effectively reduces mortality and pancreatic damage during acute pancreatitis. Thus, positive effects of EP on the course of ANP in rats may have important implications, indicating that EP is a promising molecule that could be used either alone or in combination with other substances for the management of ANP.

\section{Acknowledgments}

This research was supported by a grant from Karadeniz Technical University, Scientific Research Projects Unit (under grant number 2008.114.002.14).

\section{Conflict of interest}

The authors declare no conflict of interest.

\section{References}

1. Cruz-Santamaría DM, Taxonera C, Giner M. Update on pathogenesis and clinical management of acute pancreatitis. World J Gastrointest Pathophysiol 2012; 3: 60-70.

2. Whitcomb DC. Clinical practice. Acute pancreatitis. N Engl J Med 2006; 354: 2142-50.

3. Klar E, Messmer K, Warshaw AL, Herfarth C. Pancreatic ischemia in experimental acute pancreatitis: mechanism, significance and therapy. Br J Surg 1990; 77: 1205-10.

4. Qu Z, Jiang Y, Wu BQ et al. Cystathionine-gamma-lyase inhibitor attenuates acute lung injury induced by acute pancreatitis in rats. Arch Med Sci 2014; 10: 825-9.

5. Beger HG, Bittner R, Büchler M, Hess W, Schmitz JE. Hemodynamic data pattern in patients with acute pancreatitis. Gastroenterology 1986; 90: 74-9.

6. Rau B, Poch B, Gansauge F, et al. Pathophysiologic role of oxygen free radicals in acute pancreatitis: initiating event or mediator of tissue damage? Ann Surg 2000; 231: 352-60.

7. Abogresha NM, Greish SM, Abdelaziz EZ, Khalil WF. Remote effect of kidney ischemia-reperfusion injury on pancreas: role of oxidative stress and mitochondrial apoptosis. Arch Med Sci 2016; 12: 252-62.

8. Faiber JL, Kyle ME, Coleman JB. Mechanisms of cell injury by activated oxygen species. Lab Invest 1990; 62: 670-9.

9. Stanfey H, Bulkley GB, Cameron JL. The role of oxygen-derived free radicals in the pathogenesis of acute pancreatitis. Ann Surg 1984; 200: 405-13. 
10. Schoenberg MH, Birk D, Beger HG. Oxidative stress in acute and chronic pancreatitis. Am J Clin Nutr 1995; 62: 1306-14.

11. Jeurnink SM, Nijs MM, Prins HA, Greving JP, Siersema PD. Antioxidants as a treatment for acute pancreatitis: a meta-analysis. Pancreatology 2015; 15: 203-8.

12. Dobsak P, Courdertot-Masuyer C, Zeller M, et al. Antioxidative properties of pyruvate and protection of the ischemic rat heart during cardioplegia. J Cardiovasc Pharmacol 1999; 34: 651-9.

13. Luan ZG, Zhang H, Ma XC, Zhang C, Guo RX. Role of high-mobility group box 1 protein in the pathogenesis of intestinal barrier injury in rats with severe acute pancreatitis. Pancreas 2010; 39: 216-23.

14. Fink MP. Ethyl pyruvate: a novel anti-inflammatory agent. J Intern Med 2007; 261: 349-62.

15. Sims CA, Wattanasirichaigoon S, Menconi MJ, Ajami AM, Fink MP. Ringer's ethyl pyruvate solution ameliorates ischemia/reperfusion induced intestinal mucosal injury in rats. Crit Care Med 2001; 29: 1513-8.

16. Yang R, Shaufl AL, Killeen ME, Fink MP. Ethyl pyruvate ameliorates liver injury secondary to severe acute pancreatitis. J Surg Res 2009; 153: 302-9.

17. Dobschuetz E, Biberthaler P, Mussack T, Langer S, Messmer K, Hoffmann T. Noninvasive in vivo assessment of the pancreatic microcirculation: orthogonal polarization spectral imaging. Pancreas 2003; 26: 139-43.

18. Groner W, Winkelman JW, Harris AG, et al. Orthogonal polarization spectral imaging: a new method for study of the microcirculation. Nat Med 1999; 5: 1209-12.

19. Schmidt J, Rattner MD, Lewandrowski K. A better model of acute pancreatitis for evaluating therapy. Ann Surg 1992; 215: 44-56.

20. Sookhal S, Wang JJ, McCourt M, Kwan W, Bouchier DH, Redmond P. A novel therapeutic strategy for attenuating neutrophil-mediated lung injury in vivo. Ann Surg 2002; 235: 283-91.

21. Lankisch PG, Pohl U, Otto J, Rahlf G. When should treatment of acute experimental pancreatitis be started? The early phase of bile -induced acute pancreatitis. Res Exp Med 1988; 188: 123-9.

22. Schierwagen C, Bylund-Fellenius AC, Lundberg C. Improved method for quantification of tissue PMN accumulation measured by myeloperoxidase activity. J Pharmacol Methods 1990; 23: 179-86.

23. Buege JA, Aust SD. Microsomal lipid peroxidation. Methods Enzymol 1978; 52: 302-10.

24. Lowry OH, Rosebrough NJ, Farr AL, Randall RJ. Protein measurement with the Folin phenol reagent. J Biol Chem 1951; 193: 265-75.

25. Riedemann NC, Guo RF, Ward PA. Novel strategies for the treatment of sepsis. Nat Med 2003; 9: 517-24.

26. Bennett-Guerrero E, Swaminathan M, Grigore AM, et al. A phase II multicenter double-blind placebo-controlled study of ethyl pyruvate in high-risk patients undergoing cardiac surgery with cardiopulmonary bypass. J Cardiothorac Vasc Anesth 2009; 23: 324-9.

27. Cheng BQ, Liu CT, Li WJ, et al. Ethyl pyruvate improves survival and ameliorates distant organ injury in rats with severe acute pancreatitis. Pancreas 2007; 35: 256-61.

28. Yang ZY, Ling Y, Yin T, et al. Delayed ethyl pyruvate therapy attenuates experimental severe acute pancreatitis via reduced serum high mobility group box 1 levels in rats. World J Gastroenterol 2008; 14: 4546-50.

29. Luan ZG, Zhang H, Ma XC, Zhang C, Guo RX. Therapeutic treatment with ethyl pyruvate attenuates the severity of liver injury in rats with severe acute pancreatitis. Pancreas 2012; 41: 729-37.
30. Luan ZG, Ma XC, Zhang H, Zhang C, Guo RX. Protective effect of ethyl pyruvate on pancreas injury in rats with severe acute pancreatitis. J Surg Res 2013; 181: 76-84.

31. Yang CJ, Chen J, Phillips AR, Windsor JA, Petrov MS. Predictors of severe and critical acute pancreatitis: a systematic review. Dig Liver Dis 2014; 46: 446-51.

32. Leung PS, Chan YC. Role of oxidative stress in pancreatic inflammation. Antioxid Redox Signal 2009; 11: 135-65.

33. Kung CW, Lee YM, Yen MH. In vivo anticoagulant effect of ethyl pyruvate in endotoxemic rats. Thromb Res 2011; 127: 582-8.

34. Crawford RS, Albadawi H, Atkins MD, et al. Postischemic treatment with ethyl pyruvate prevents adenosine triphosphate depletion, ameliorates inflammation, and decreases thrombosis in a murine model of hind-limb ischemia and reperfusion. J Trauma 2011; 70: 103-10.

35. van Zoelen MA, Bakhtiari K, Dessing MC, et al. Ethyl pyruvate exerts combined anti-inflammatory and anticoagulant effects on human monocytic cells. Thromb Haemost 2006; 96: 789-93.

36. Zhang X, Wu D, Jiang X. ICAM-1 and acute pancreatitis complicated by acute lung injury. JOP 2009; 10: 8-14.

37. Murakami H, Nakao A, Kishimoto W, Nakano M, Takagi H. Detection of O2- generation and neutrophil accumulation in rat lungs after acute necrotizing pancreatitis. Surgery 1995; 118: 547-54.

38. Matone J, Moretti Al, Apodaca-Torrez FR, Goldenberg A. Ethyl-pyruvate reduces lung injury matrix metalloproteinases and cytokines and improves survival in experimental model of severe acute pancreatitis. Acta Cir Bras 2013; 28: 559-67.

39. Papachristou GI. Prediction of severe acute pancreatitis: current knowledge and novel insights. World J Gastroenterol 2008; 14: 6273-5. 